\title{
Intelligent Growth and Macroeconomic Performance of EU Member Countries in the Framework of Europe 2020
}

\author{
Papailiou Paraskevi ${ }^{1}$, Komninos Dimitrios $^{2}$, Dermatis Zacharias ${ }^{3}$, Anastasiou Athanasios ${ }^{4}$, Liargovas Panagiotis ${ }^{5}$ \\ ${ }^{1} \mathrm{MSc}$, Department of Economic Studies, University of Peloponnese, Greece \\ ${ }^{2} \mathrm{PhD}$ Candidate, Department of Economic Studies, University of Peloponnese, Greece \\ ${ }^{3} \mathrm{PhD}$, Department of Economic Studies, University of Peloponnese, Greece \\ ${ }^{4}$ Assistant Professor of Department of Economic Studies, University of Peloponnese, Greece \\ ${ }^{5}$ Professor of Department of Economic Studies, University of Peloponnese, Greece \\ Correspondence: Anastasiou Athanasios, Assistant Professor of Department of Economic Studies, University of \\ Peloponnese, Greece.
}

Received: April 3, 2018

doi:10.11114/aef.v5i4.3385
Accepted: June 14, 2018 Available online: June 24, 2018

URL: https://doi.org/10.11114/aef.v5i4.3385

\begin{abstract}
Europe 2020 is the new ten-year strategy of the European Union for smart, sustainable and inclusive growth. This work analyzes the role of smart growth within the Europe 2020 strategy. "Smart growth" means strengthening knowledge and innovation by improving the quality of education, enhancing research performance, promoting innovation and transferring knowledge across the EU.

In this study we create a thematic smart growth index, which consists of individual indicators proposed by the European Commission and presents the ranking of EU member countries in this index. The composite indicator of Europe 2020 by Pasimeni (2011) is taken as the basis for the creation of the indicator.

Then, with the help of regression models, the relationship between the index and some macroeconomic variables is examined to examine the impact of the variables on the performance of the E-28 countries and their overall competitiveness. The results show that macroeconomic indicators of public finances, such as the rate of change in GDP per capita, government debt and deficit levels, are not key success factors for smart growth.
\end{abstract}

Keywords: smart growth, Europe 2020, Europe 2020 indicator, macroeconomic variables.

\section{Introduction}

In March 2010, in the wake of the current economic and financial crisis and following the failure of the Lisbon Strategy, the European Council adopts a new strategy aimed at the collective effort of EU Member States to develop smart, sustainable and inclusive growth. The strategy was named "Europe 2020" and includes three development priorities and five objectives to be implemented by 2020 and covering issues related to employment, education, innovation, climate change and social exclusion. Also, the Commission has adopted 7 actions - flagship initiatives that have to be implemented at national, European level with the aim of entering the EU into a new and more sustainable development path.

The present work aims to present the "smart growth" priority of the Europe 2020 strategy and to highlight the macroeconomic performance of EU Member States in this context. For this purpose, an indicator for smart growth will be formed and it will be examined how it is affected by various macroeconomic variables such as GDP per capita rate of change, consolidated general government debt as \% of GDP, general government deficit / surplus as \% of GDP.

\section{Theoretical Background}

\subsection{Smart Growth - An Economy Based on Knowledge and Innovation}

Smart growth means stimulating knowledge and innovation by improving the quality of education, enhancing research performance, promoting innovation and transferring knowledge across the EU, addressing European and global societal challenges and increasing the competitiveness of the European economy. In the midst of a crisis, Europe is making little 
progress in some areas compared to the rest of the world. These areas, among others, include productivity, education and the aging of the population.

In particular, low productivity compared to other countries such as the USA and Japan is due to low levels of investment in R \& D and innovation, inadequate use of information and communications and the difficulty of accessing certain sectors of society to innovation.

With regard to education, about $25 \%$ of students have difficulty reading, while many are young people who either drop out of their studies without acquiring any skills, or even acquired, do not meet the needs of the labor market. Less than one third of Europeans aged 25-34 have a university degree, while at the same time in the US the figure is $40 \%$ and more than 50\% in Japan. Finally, with regard to education, only two of the European universities are included in the list of the 20 best universities in the world (academic rankings of world universities 2010).

Increased life expectancy in the EU coupled with declining birth rates create a small proportion of workers who are in charge of maintaining a large number of retirees. People aged over 60 grow at twice the rate of 2007, about two million a year compared to one million previously.

\subsection{Intelligence Competitiveness. Definition and Analysis of Smart Growth Objectives}

As stated above, the aim of the strategy is to increase the EU's competitiveness. In terms of competitiveness, many are the ones who have given a definition of its meaning. Gros and Roth in their 2012 report on Europe's competitiveness report a few concepts. For Krugman competitiveness is the ability of a country to produce efficiently with its given resources. Porter (2011) at OECD (2012:29) also defines the state of competitiveness as "the productivity with which a state uses its human, capital, and natural resources." WEF's Global Competitiveness Report 2010-2011 defines competitiveness as "the (Schwab, 2010, p. 4) For Gros and Roth (2012), a nation's competitiveness refers to its ability to use its available resources as much as possible the best possible lively to generate long-term socially and ecologically sustainable wealth, thus providing a sustainable increase in living standards of its citizens.

In their study (Gros \& Roth, 2012) they are looking at the 5 objectives of the Europe 2020 strategy and presenting the extent to which each strategy has an impact. On the objectives of smart growth priority, they are studying innovation, employment and education.

The Europe 2020 Competitiveness Assessment Report for 2014 was based on data from institutions such as Internet rates and unemployment rates, and data from the proposals of the 2010 EOS (Global Economic Forum $(2012,2014)$ ) Executive Research. Firstly, there is a low EU position on all four axes that make up the intelligent sub-index compared to other advanced economies. These axes are:

1. Business Environment (4.05)

2. Digital Agenda $(4,71)$

3. Innovative Europe (4.34)

4. Education and training (5.00)

The crisis has had a strong impact on the EU and ranks it with an average of 4.15 in the pillar of smart growth with unfavorable effects such as rising unemployment and rigidities in the labor market.

\section{Smart Deployment Measurement (Index)}

\subsection{Methodology}

In order to measure the performance of the EU Member States in achieving the objectives of smart growth, we will create a specific indicator, as proposed by Passimeni $(2011,2013)$, in order to quantify the relative position of each state and we check how it is affected by various macroeconomic variables.

The indicators proposed by the European Commission for the whole Europe 2020 strategy are as follows:

$>$ Percentage of Higher Education Graduates (PHEG)

> Gross Domestic Expenditure on Research and Development (GDERD)

$>$ Greenhouse Gas Emissions (GGE)

$>$ Share of Renewable Energy in Gross Final Consumption (SREGFC)

$>$ Energy intensity of the economy (EIE)

$>$ Employment rate of the 20-64 Age Group (ERAG)

$>$ Early School Leavers (ESL)

$>$ Population at Risk of Poverty or Exclusion (PRPE) 
Pasimeni (2011), in order to create a composite indicator for the strategy, creates a specific indicator for each of the three main dimensions of the Europe 2020 strategy. It normalizes the above indicators and creates thematic indicators: the smart growth index (SGI) Sustainable Development Index (SDI), and the Inclusive Growth Index (IGI), which in turn make up the Europe 2020 indicator. Thus, Higher Education (PHEG) and Gross R \& D expenditure for Pasimeni (2011a) ) are considered as the main factor of smart development dimension and based on this position will be the creation of thematic index in this paper.

Thus, for positive indicators where the highest price represents a higher performance, such as higher education (PHEG) and gross R \& D expenditure (GDERD), the main drivers of the smart growth dimension and their measurement are considered, so that all values included are between one and zero, we use the following formula:

$$
x_{i}^{c}=\frac{x_{i}^{c}-\min _{k}\left\{x_{i k}\right\}}{\max _{k}\left\{x_{i k}\right\}-\min _{k}\left\{x_{i k}\right\}}
$$

where $i$ represents the PHEG, GDERD indicators, $c$ the country, and $\max _{\mathrm{k}}$ and $\min _{\mathrm{k}}$ the maximum and minimum value of the index over the entire length of the available time period.

While for the "early-maturity" index (ESL), which is negative, the lower the price represents a higher return, we will use the following formula:

$$
x_{i}^{c}=\frac{\max _{\mathrm{k}}\left\{x_{i k}\right\}-\mathrm{x}_{\mathrm{ic}}}{\max _{\mathrm{k}}\left\{x_{i k}\right\}-\min _{\mathrm{k}}\left\{\mathrm{x}_{\mathrm{ik}}\right\}}
$$

The normalized indices can now be summed using the numerical summation method, calculating the average of the values of the various components for each index:

$$
I_{g}=\frac{1}{n} \sum_{i-1}^{n} X_{i}
$$

or the geometric aggregation method

$$
l_{g}=\left(\prod_{i=1}^{n} \mathrm{X}_{\mathrm{i}}^{\mathrm{c}}\right)^{1 / n}
$$

Because the geometric summation method gives higher values to pointers that are more homogeneous in their constituents, we will use this method to create the thematic index of smart growth.

It will also evaluate the "statistical significance" of the estimated correlations, ie the degree of confidence that the true correlation is close to the estimate.

The mathematical model, which we choose to adapt to our data, is linear.

The model to be assessed is in the form of:

$$
r=a+b x+e
$$

for single regressions and

$$
\Upsilon=a_{0}+a b_{1} x_{1}+b_{2} x_{2}+a b_{3} x_{3}+e
$$

for multiple regressions

Where,

$>\mathrm{Y}$ is the dependent variable

$>\mathrm{X}$ are the independent variables

$>\mathrm{a}, \mathrm{b}$ and e are real numbers

$>\mathrm{e}$ is the error

The conditions to apply to regression are as follows:

$>\quad$ the values of $\mathrm{x}$ and $\mathrm{Y}$ are independent of each other. For each value of $\mathrm{x}$ in the sample the values of $\mathrm{Y}$ must follow the Normal distribution.

$>$ The relationship between $\mathrm{x}$ and $\mathrm{Y}$ must be linear

$>$ Measurements of values of $\mathrm{x}$ variables should not include errors

3.2 Data

Yearly data from Eurostat (2015) was used to construct the thematic index. Two sets of 28 observations were created for each group and a total of 56 observations, covering the 28 EU Member States for 12 years. The first group refers to 
the years 2003 to 2008, a pre-crisis period, and the second group refers to the years 2009 to 2014 . The dependent model variable is the thematic index of smart growth. Although the Europe 2020 strategy has begun in 2010 and covers the 2010-2020 period, data availability for all variables starts in 2003 and it is interesting to analyze the whole period in order to check the EU situation 28 before and after the crisis.

The variables used to construct the smart growth index are the three below and are analyzed according to (Pasimeni, 2011) as follows:

\section{Percentage of Higher Education Graduates (PHEG)}

It includes the percentage of the population aged 30-34 who have successfully completed the university on the basis of the International Standard Classification of Education at level 5-8. The objective of the indicator is to increase the share of people aged 30-34 who have completed tertiary or equivalent education to at least $40 \%$ in 2020.

\section{Gross Domestic Expenditure on Research and Development (GDERD)}

$\mathrm{R} \& \mathrm{D}$ transfers resources between units, organizations and sectors and it is important to monitor the flow of funds.

\section{Early school leavers for ages 18-24 (ESL)}

The indicator includes the proportion of the population aged 18-24 with lower secondary education who are not involved in further education or training. From 20 November 2009, this indicator is based on the annual averages of quarterly data rather than a single quarterly report in the spring. Early school leavers refer to people aged 18-24 who meet the following two conditions: first, the highest level of education or training achieved is $0,1,2$ or 3 in accordance with International Standards and secondly, the respondents stated that they did not receive any education or training during the 4 weeks preceding the survey (numerator). The denominator includes the entire population of the same age group without answering questions about the highest level of education or training achieved and about participation in education and training. Both numerators and denominators come from the EU Labor Force Survey.

The dimension of smart growth is complementary to economic growth, so it will be interesting to compare it with other dimensions of economic growth available in the bibliography.

The macroeconomic variables to be considered in the model and compared to the smart growth indicator are the general government gross debt (code: gov_10dd_edpt,) the general government deficit or surplus (code: tec00127), calculated as a percentage of GDP and finally the rate of change of per capita GDP (code: nama_10_gdp,). All data on macroeconomic variables were collected by Eurostat.

\section{Empirical Analysis for EU Countries}

\subsection{Factors Affecting the Index}

Looking at the three macroeconomic indicators mentioned in the previous section, ie real GDP growth, the consolidated general government gross debt as a percentage of GDP and the general government budget deficit / surplus as a percentage of GDP compared to the smart growth rate, we find the extent to which the indicator is affected by the above variables and thus explain the differences in the performance of the EU Member States.

\section{Coefficients of linear correlation}

First, we see that all p-values are $0.000<0.01$, so there is a statistically significant linear correlation between the pairs of variables. From the correlation, it appears that the independent variable "FREQUENCY DELAY" is weakly correlated with the variable "GDP CHANGE" (0.492) while there is a moderate negative linear correlation with the variable "DEBT OF GENERAL GOVERNMENT" (-0.635). Also, there is an average negative correlation between the variable " DEBT OF GENERAL GOVERNMENT " and "GDP CHANGE" (-0,609). But all linear correlations are not strong because their absolute values are not close to the unit. Among the variables "BENEFITS" and "Failure" is the largest negative correlation with $-0.635 * *$.

\section{Construction of Multiple Linear Regression model}

In order to compare the pointer to the variables, we will regress our data using the SPSS statistical program. The interpretative variables are "GDP CHANGE" for the rate of change in GDP per capita, " DEBT OF GENERAL GOVERNMENT " for the general government debt, "DEFENDANCE" for the general government deficit or surplus plus a dummy variable "DUMMY" which takes the ' 0 ' values for the 2003-2008 pre-crisis period and ' 1 ' for the 2009-2014 period.

The results of the regressions are presented in Tables 1 and 2 . 
Table 1. Impact on the SGI index from the gradual introduction of variables, pooled sample 2003-2008 and 2009-2014, REGRASSIONS 1-5.

\begin{tabular}{|c|c|c|c|c|c|}
\hline \multirow[t]{3}{*}{ Interpretative variables } & \multicolumn{5}{|c|}{ Variant variable: Smart Development index } \\
\hline & \multicolumn{5}{|c|}{ Calculators estimations } \\
\hline & 1 & 2 & 3 & 4 & 5 \\
\hline Index & $0,581(-0,030)$ & $\begin{array}{c}0,240 \\
(0,033)\end{array}$ & $\begin{array}{c}0,345 \\
(0,064)\end{array}$ & $\begin{array}{c}0,247 \\
(0,027)\end{array}$ & $\begin{array}{r}0,374 \\
(0,043)\end{array}$ \\
\hline Gross GDP & $-0,063 * * *(0,009)$ & $\begin{array}{c}0,001 \\
(0,007)\end{array}$ & & & \\
\hline Government debt & & & $\begin{array}{c}0,212^{* *} \\
(0,099)\end{array}$ & $\begin{array}{l}-, 0008 \\
(0,043)\end{array}$ & \\
\hline Gap/surplus & & & & & $\begin{array}{c}-0,028 * \\
* * \\
(0,010)\end{array}$ \\
\hline DUMMY & & $\begin{array}{c}0,443 \\
(0,038)\end{array}$ & & $\begin{array}{c}0,441 \\
(0,027)\end{array}$ & \\
\hline $\mathbf{R}$ & 0,674 & 0,920 & 0,280 & 0,920 & 0,370 \\
\hline $\mathbf{R 2}$ & 0,454 & 0,847 & 0,078 & 0,847 & 0,137 \\
\hline ADJUSTED R2 & 0,444 & 0,841 & 0,061 & 0,841 & 0,121 \\
\hline DURBIN-WATSON & 1,300 & 1,831 & 0,44 & 1,837 & 0,673 \\
\hline $\mathbf{N}$ & 56 & 56 & 56 & 56 & 56 \\
\hline
\end{tabular}

Note: $* * *=<1 \%$ significance level; $* *=<5 \%$ level of significance; $*=<10 \%$ level of significance. Numbers in brackets are a standard error

Table 2. Effect on the SGI index from the gradual introduction of variables, pooled sample 2003-2008 and 2009-2014, REGRASSIONS 6-10.

\begin{tabular}{|c|c|c|c|c|c|}
\hline \multirow[t]{3}{*}{ Interpretative variables } & \multicolumn{5}{|c|}{ Variant variable: Smart Development index } \\
\hline & \multicolumn{5}{|c|}{ Calculators estimations } \\
\hline & 6 & 7 & 8 & 9 & 10 \\
\hline Index & $0,252(0,020)$ & $\begin{array}{l}0,691 \\
(0,072)\end{array}$ & $\begin{array}{l}0,564 \\
(0,048)\end{array}$ & $\begin{array}{l}0,354 \\
(0,062)\end{array}$ & $\begin{array}{l}0,683 \\
(0,072)\end{array}$ \\
\hline Gross GDP & & $\begin{array}{l}-0,075^{* * *} \\
(0,012)\end{array}$ & $\begin{array}{l}-0,061 * * * \\
(0,011)\end{array}$ & & $\begin{array}{l}-0,072 * * * \\
(0,012)\end{array}$ \\
\hline Government debt & & $\begin{array}{l}-0,158 \\
(0,094)\end{array}$ & & $\begin{array}{l}-0,025^{*} \\
(0,013)\end{array}$ & $\begin{array}{l}-0,233 \\
(0,107)\end{array}$ \\
\hline Gap/surplus & $0,005(0,005)$ & & $\begin{array}{l}-0,004 \\
(0,009)\end{array}$ & $\begin{array}{l}0,057 \\
(0,125)\end{array}$ & $\begin{array}{l}-0,014 \\
(0,010)\end{array}$ \\
\hline DUMMY & $0455(0,029)$ & & & & \\
\hline $\mathbf{R}$ & 0,922 & 0,694 & 0,675 & 0,374 & 0,708 \\
\hline $\mathbf{R 2}$ & 0,851 & 0,482 & 0,456 & 0,14 & 0,502 \\
\hline ADJUSTED R2 & 0,845 & 0,62 & 0,436 & 0,374 & 0,473 \\
\hline DURBIN-WATSON & 1,818 & 1,462 & 1,292 & 0,655 & 1,51 \\
\hline $\mathbf{N}$ & 56 & 56 & 56 & 56 & 56 \\
\hline
\end{tabular}

Note: $* * *=<1 \%$ significance level; $* *=<5 \%$ level of significance; $*=<10 \%$ level of significance. Numbers in brackets are a standard error

The first model checks whether a country's growth rate affects its performance relative to the smart growth index. As we can see from the data, the effect is negative and statistically significant while the data variability is $45.4 \%$. ( $\mathrm{R} 2=$ $0.454 \%)$. That is, $45.4 \%$ of the variance of the SGI is interpreted by the variation in a country's growth rate. Also, if we calculate the linear correlation coefficient we will see that it has a strong value (0.674). The result of the Durbin-Watson coefficient of 1,300 interprets the positive correlation of residues.

The model we have adapted to the two variables is in the form:

$$
r=a+b x+e
$$

In particular, what follows is: $\mathrm{SGI}=0.581-0.063$ (GDP CHANGE) 
By checking the regression coefficient $b$, ie the coefficient of the change in per capita GDP, we observe that $t=-6,705$ and the value sig.0,000<0,01. Therefore, the coefficient is statistically significant and it interprets statistically significant the SGI at a materiality level of $1 \% .45 .4 \%$ of the indicator's variance is interpreted by the fluctuation in the rate of change in GDP. Also, the estimated model indicates that when the rate of change of GDP is increased by one unit, the index is expected to be on average down by 0.063 points.

The $95 \%$ confidence interval for the true value of $b$ is $(-0.082,-0.044)$. We observe that it does not contain zero, so the assumption that $\beta$ can get the value 0 is rejected at a 5\% significance level. Also, whatever price we want to control that is not in this time will be rejected at $\mathrm{a}=5 \%$.

The rate of variability of the variable from the others is $0 \%$, while the VIF value is $1<2$, so there is no problem of collinearity. This is also checked by the Condition Index column of the Collate Diagnostics table if all values are lower than 15.

Additionally, dummy variable Dummy shows that the rate of change in GDP does not statistically represent the SERR index at a $5 \%$ significance level as $t=0.132$ and the value of sig.896>0.05. Therefore, the coefficient is not statistically significant, although the coefficient of assay is quite high $(\mathrm{R} 2=0.847)$.

Looking at the financial profile of the EU-28 countries, we start with the relationship between the SGI index and the general government debt as a percentage of GDP. There is a relatively weak positive relationship between the two variables $(R 2=0,078)$, suggesting that maintaining low debt is not necessarily conducive to good performance in terms of the Europe 2020 strategy and the smart growth indicator, and on the other hand, the increase in public debt does not facilitate any improvement in the index. The linear correlation coefficient has a low value $(0.280)$. The result of the Durbin-Watson 0.440 coefficient explains the low correlation of residues.

The resulting mathematical model is:

\section{SGI Index $=0.345+0.212$ (DEBT OF GENERAL GOVERNMENT)}

By checking the regression coefficient $b$, ie the coefficient of the GDP change rate, we can see that $t=2,141$ and the value sig.0,037<0,05. Therefore, the coefficient is statistically significant and it interprets the SGI index statistically significant to a $5 \%$ materiality level. The $7.80 \%$ of the indicator's variance is interpreted by the fluctuation in the rate of change of GDP, which means that this ratio is weak. Also, the estimated model indicates that, when the rate of change in GDP is increased by one, the index is expected to be on average increased by 0.212 units.

The $95 \%$ confidence interval for the true value of $\mathrm{b}$ is $(0.013,0.410)$. We observe that it does not contain zero, so the assumption that $\beta$ can get the value 0 is rejected at a $5 \%$ significance level. Also, whatever price we want to control that is not in this time will be rejected at a $=5 \%$.

The rate of variability of the variable from the others is $0 \%$, while the VIF value is $1<2$, so there is no problem of collinearity. This is also checked by the Condition Index column of the Collate Diagnostics table if all values are lower than 15.

Adding the dummy Dummy then we notice that the significance of 5\% is significant for DEBT OF GENERAL GOVERNMENT as $\mathrm{t}=-0,180$ and the value sig. $85,858>0,005$. Therefore, the coefficient is not statistically significant, although the coefficient of determination is quite high $\left(R^{2}=0.847\right)$.

We are going to control the relationship of the SGI index and the general government deficit / surplus as a percentage of GDP

The relationship between the two coefficients is negative and quite weak $(\mathrm{R} 2=0.137)$. Factor DEFICIT_SURPLUS is statistically significant $(\mathrm{t}=-2,925$ and $\mathrm{sig}=0,005)$ at a $1 \%$ significance level.

The coefficient of linear correlation has a low value (0.370). The result of the Durbin-Watson 0.673 coefficient explains the low correlation of residues.

The resulting mathematical model is:

SGI $=0.374-0.028$ (DEFICIT_SURPLUS)

$13.7 \%$ of the fluctuation of the indicator is interpreted by the general government deficit or surplus. Also, the estimated model indicates that when the government deficit increases by one unit, the index is expected to be on average down by 0.028 points.

The $95 \%$ confidence interval for the true value of $b$ is $(-0.048,-0.009)$. We observe that it does not contain zero, so the assumption that $\mathrm{b}$ can get the value 0 is rejected at a $5 \%$ significance level. Also, whatever price we want to control that is not in this time will be rejected at $\mathrm{a}=5 \%$. 
The rate of variability of the variable from the others is $0 \%$, while the VIF value is $1<2$, so there is no problem of collinearity.

Then adding dummy Dummy we can see that DEFICIT_SURPLUS does not statistically interpret the SGI at a 5\% significance level as $t=1,163$ and the value of sig.2,250>0,005. Therefore, the coefficient is not statistically significant, although the coefficient of assay is quite high $(\mathrm{R} 2=0.851)$.

We then create a model with the coexistence of two independent variables. The model we adapted to the three variables is in the form:

$$
r=a+b_{1} x_{1}+b_{2} x_{2}+e
$$

First, we test how the SGI indicator is affected when the variable CHANGE GDP and DEBT OF GENERAL GOVERNMENT coexist. It is noted that the relationship between the three variables is negative and moderate $\left(\mathrm{R}^{2}=\right.$ 0.482 ) and that the performance of the (R-square) improved by 2.8 percentage points. The coefficient of linear correlation has a high value (0.694). The result of the Durbin-Watson coefficient 1.462 interprets the positive correlation of residues). The coefficient CHANGE_GDP is statistically significant $(\mathrm{t}=-6,420$ and $\mathrm{sig}=0,000)$. It therefore interprets the SGI statistically significant at a $1 \%$ materiality level. Instead, the DEBT OF GENERAL GOVERNMENT coefficient is not statistically significant $(t=-1,668$ and $\mathrm{sig}=0,101)$. Therefore, it does not interpret the SGI statistically significant.

The resulting mathematical model is:

\section{SGI index $=0.691-0.075$ (CHANGE_GDP) - 0.158 (DEBT OF GENERAL GOVERNMENT)}

Also, the estimated model indicates that when the rate of change of GDP is increased by one unit, the index is expected to be, on average, reduced by 7.5 percentage points. While DEBT OF GENERAL GOVERNMENT is statistically significant, as it increased by one unit it would cause a decrease in the index by 15.8 percentage points.

The $95 \%$ confidence interval for the actual value of $\beta 1$ is $(-0.098,-0.051)$ and $\beta 2$ is $(-0.347 .0 .032)$. We note that $\beta 1$ does not contain zero, so the assumption that $\beta 1$ can get the value 0 is rejected at a $5 \%$ significance level. Also, whatever price we want to control that is not in this time will be rejected at $a=5 \%$. The opposite holds for $\beta 2$ which contains zero.

The percentage of variability of the variable from the other variables is $0.371 \%$ for both variables, while the VIF value is $1.59<2$ for both variables, so there is no problem of collinearity. This is also checked by the Condition Index column of the Collate Diagnostics table if all values are lower than 15.

Then we check how the SGI indicator is affected when the variable CHANGE OF GDP and DEFICIT SURPLUS are present. It is noted that the relationship is negative and moderate $\left(R^{2}=0.456\right)$ and that the interpretive capacity (R-square) has improved by 0.2 percentage points. The coefficient of linear correlation has a high value $(0.675)$. The result of the Durbin-Watson coefficient of 1,292 interprets the positive correlation of residues. ). The CHANGE of GDP is statistically significant $(\mathrm{t}=-5,580$ and sig $=0,000)$. It therefore interprets the SGI statistically significant at a $1 \%$ materiality level. Instead, the DEFICIT_SURPLUS is not statistically significant $(\mathrm{t}=-0,432$ and sig $=0,667)$. Therefore, it does not interpret the SGI statistically significant.

The resulting mathematical model is:

\section{SGI Index $=0.564-0.061$ (CHANGE of GDP) - 0.004 (DEFICIT_SURPLUS)}

Also, the estimated model indicates that, when GDP is increased by one unit, the index is expected to be on average down by 6.1 percentage points. While Failure if statistically significant, as it increased by one unit, it would reduce the index by 0.4 percentage points.

The $95 \%$ confidence interval for the actual value of b1 is $(-0.082,-0.039)$ and $b 2$ is $(-0.022 .0 .014)$. We note that b1 does not contain zero, so the assumption that b1 can get the value 0 is rejected at a 5\% significance level. Also, whatever price we want to control that is not in this time will be rejected at $\mathrm{a}=5 \%$. The opposite holds for $\mathrm{b} 2$ which contains zero.

The rate of variability of the variable from the other variables is $0.242 \%$ for both variables, while the VIF value is 1.32 $<2$ for both variables, so there is no problem with collinearity. This is also checked by the Condition Index column of the Collate Diagnostics table if all values are lower than 15.

By checking the SGI index when the variables DEBT of GENERAL GOVERNMENT and DEFICIT_SURPLUS coexist, it is observed that the relationship is between the three variable variables $\left(R^{2}=0,140\right)$ and that the $R$-square is quite low. The coefficient of linear correlation has a low value (0.374). The result of the Durbin-Watson coefficient 0.655 explains the low correlation of residues. However, the coefficients do not statistically explain the SGI index at a 5\% significance level as all sig values are greater than 0.05 . However, at a $10 \%$ significance level, the DEFICIT_SURPLUS 
is statistically significant $(t=-1,953$ and $\operatorname{sig}=0,056)$. It therefore interprets the SGI statistically significant to a $10 \%$ materiality level. Instead, the DEBT of GENERAL GOVERNMENT coefficient is not statistically significant $(\mathrm{t}=$ $-0,455$ and sig $=0,651)$. Therefore, it does not interpret the SGI statistically significant at any materiality level.

The resulting mathematical model is:

SGI $=0.354-0.025$ (DEFICIT_SURPLUS) +0.057 (DEBT of GENERAL GOVERNMENT)

Also, the estimated model indicates that, when DEFICIT_SURPLUS increases by one unit, the index is expected to be on average down 2.5 percentage points. While DEBT of GENERAL GOVERNMENT was statistically significant, as it increased by one unit it would increase the index by 5.7 percentage points.

The $95 \%$ confidence interval for the actual value of b1 is $(-0.050,-0.039)$ and $b 2$ is $(-0.194 .0 .307)$. We observe that both contain zero, so the assumption that $\mathrm{b} 1$ and $\mathrm{b} 2$ can get the value 0 is not rejected at a 5\% significance level. Also, whatever price we want to control that is not in this time will be rejected at $\mathrm{a}=5 \%$.

The percentage of variability of the variable from the others is $0.404 \%$ for both variables, while the VIF value is 1.676 $<2$ for both variables, so there is no problem of collinearity. This is also checked by the Condition Index column of the Collate Diagnostics table if all values are lower than 15.

Finally, we create a model with the coexistence of all the independent variables. The model we adapted the variables is of the form:

$$
\Upsilon=a+\beta_{1} X_{1}+\beta_{2} X_{2}+\beta_{3} X_{3}+e
$$

It is noted that the relationship is moderate between the three variables $\left(\mathrm{R}^{2}=0.502\right)$ and that the $\mathrm{R}$-square performance was improved by 4.8 percentage points. The coefficient of linear correlation has a high value $(0.708)$. The result of the Durbin-Watson coefficient 1,510 interprets the positive correlation of residues.

Regarding the statistical significance of the coefficients, we observe that the CHANGE OF GDP interprets the SGI statistically significant at a $1 \%$ significance level as its values are $(t=-6,142$ and $\operatorname{sig}=0,000)$. The DEBT of GENERAL GOVERNMENT factor interprets the SGI statistically significant to a 5\% significance level as its values are $(\mathrm{t}=-2,177$ and sig $=0,034)$. Instead, the DEFICIT_SURPLUS is not statistically significant $(\mathrm{t}=-1,449$ and $\operatorname{sig}=$ $0,153)$. Therefore, it does not interpret the SGI statistically significant at any materiality level.

The resulting mathematical model is:

\section{SGI Index $=0.683-0.072$ (CHANGE GDP) -0.233 (DEBT GENERAL GOVERNMENT) -0.014} (DEFICIT_SURPLUS)

Also, the estimated model indicates that when the CHANGE GDP increases by one unit, the index is expected to be on average down by 7.2 percentage points. When DEBT of GENERAL GOVERNMENT is increased by one unit, the index is expected to be, on average, reduced by 23.3 percentage points. While DEFICIT_SURPLUS is statistically significant, as it increased by one unit, it would reduce the index by 1.4 percentage points.

The $95 \%$ confidence interval for the actual value of b1 is $(-0.095,-0.048)$, b2 is $(-0.448,-0.018)$ and b3 $(-0.034 .0 .005)$. We note that $\mathrm{b} 1$ and $\mathrm{b} 2$ do not contain zero, so the assumption that $\mathrm{b} 1$ and $\mathrm{b} 2$ can get the value 0 is rejected at a 5\% significance level. Also, whatever price we want to control that is not in this time will be rejected at a $=5 \%$. While $\beta 3$ contains zero, therefore the assumption that $\beta 3$ can get the value 0 is not rejected at a 5\% significance level. Also, any price we want to control that is not in that time will not be rejected at a $=5 \%$. The percentage of variability of the variable from the others is equal to $0.39 \%$ for CHANGE GDP, $0.52 \%$ for DEBT OF GENERAL GOVERNMENT and $0.421 \%$ for DEFICIT_SURPLUS. The VIF value is 1,638 for CHANGE GDP, 2,081 for DEBT OF GENERAL GOVERNMENT and 1,727 for DEFICIT_SURPLUS. So there's a collusion problem for DEBT of GENERAL GOVERNMENT with an increased standard error (st.error $=0.107$ ), although the values in the Condition Index column of the Collate Diagnostic Table are less than 15.

In conclusion, we find that the most statistically significant variable in simple regressions is the rate of change of GDP, with negative and low interpretative capacity. Whenever the simple regressions and the dummy variable are added, the coefficients are not statistically significant and do not affect the variable under consideration, which means that the separation of the periods before and after the crisis does not help to interpret the model. We also notice that whenever there is a rate of change of GDP in the model, either alone or in combination with another variable, then the GDP factor is always statistically significant. From this we can probably conclude that the rate of growth of a country, compared to the other two factors under consideration, is one that affects, to a low degree, its performance in the priority of smart growth of the Europe 2020 strategy. 


\section{Conclusion}

In this paper, the priority of the smart growth of the Europe 2020 strategy has been studied. To this end, the objectives of the strategy have been presented at national level as well as the flagship initiatives. Based on the literature, the EU's competitiveness in terms of smart growth was examined, and finally, reference was made to Greece's position on this priority.

A thematic indicator was created to measure the progress of EU member countries on smart growth objectives, and two seasons were separated to look at the indicator before and after the onset of the crisis. In the first period, Sweden, Malta and Finland held the top positions while in the second period Malta, the Netherlands and Spain. Greece, before the crisis, was in a low position (22nd) in the second period worsened its position and was in 26th place.

At European level, analysis shows that macroeconomic indicators, such as the rate of change in GDP per capita, government debt and general government deficit or surplus, are not one of the most important factors determining the success of the pillar of smart growth without this to mean that they are not important objectives by themselves.

In the present study there was no further possibility to control other factors that affect the performance of smart growth. According to international literature, such factors are the quality of governance, levels of corruption, the efficiency of governments, and informal institutions such as social capital. These factors (PASIMENI, 2011), as they have been investigated, are most likely to contribute to the achievement of the Europe 2020 objectives and, by extension, smart growth, from macroeconomic indicators of public accounts

\section{References}

Colak, M. S., \& Ege, A. (2011). An Assessment of EU 2020 Strategy: Too Far to Reach? Springer.

European Commission. (2010). Europe 2020 Flagship Initiative, Innovation Union.

European Commission. (2010). Youth on the Move, An initiative to unleash the potential of young people to achieve smart, sustainable and.

European Commission. (2010). Youth on the Move, An initiative to unleash the potential of young people to achieve smart, sustainable and inclusive growth in the European Union .

European Commission (2010). Europe 2020, A strategy for smart, sustainable and inclusive growth. Brussels.

Eurostat. (2015). Smarter, greener, more inclusive.Indicators to support the Europe 2020 strategy.

Forum, W. E. (2012). The Europe 2020 Competitiveness Report: Building a More Competitive Europe.

Forum, W. E. (2014). The Europe 2020 Competitiveness Report: Building a More Competitive Europe.

Gros, D., \& Roth, F. (2012). The Europe 2020 strategy, Can it maintain the EU's competitiveness in the world?

Brussels: Centre for European policy studies

Heuse, P., \& Zimmer, H. (2011). The Europe 2020 strategy.

Hudrliková, L. (2013). Composite indicators as a useful tool for international comparison: The Europe 2020 example. Prague Economic Papers. https://doi.org/10.18267/j.pep.462

Liargovas, P.,\& Schnitzis, B. (2015). Strategic Plan for Economic and Social Development "Europe 2020": Trends, perspectives and the position of Greece. GSEE Labour Institute

Martos, M. J., \& Domínguez, Á. S. (2013). Europe 2020 strategy: a strategy for which type of growth?

Natali, D. (2010). The Lisbon Strategy, Europe 2020 and the crisis in between. Bruxelles: European social Observatory - EU 2020 Contract - Deliverable 4.

OECD. (2012). Competitiveness and Private Sector Development. UKRAINE Sector competitiveness strategy.

Pasimeni, P. (2011). Measuring Europe 2020: a new tool to assess the strategy.

Pasimeni, P. (2011a). The Europe 2020 Index.

Saltelli, A., D’Hombres, B., Jesinghaus, J., Manca, A. R., Mascherini, M., \& Nardo, M., et al. (2010). Indicators for European Union Policies.Business as usal? Springer.

Web pages:

http://www.shanghairanking.com/ARWU2010.html

http://ec.europa.eu/europe2020/europe-2020-in-a-nutshell/priorities/smart-growth/index_el.htm

http://eur-lex.europa.eu/legal-content/EL/TXT/?uri=URISERV:si0016

http://ec.europa.eu/europe2020/europe-2020-in-a-nutshell/targets/index_el.htm 
https://www.espa.gr/el/pages/staticEurope2020.aspx

http://europa.eu/rapid/press-release_IP-10-1609_el.htm

http://eur-lex.europa.eu/legal-content/EL/TXT/?uri=URISERV:si0016

\section{Copyrights}

Copyright for this article is retained by the author(s), with first publication rights granted to the journal.

This is an open-access article distributed under the terms and conditions of the Creative Commons Attribution license which permits unrestricted use, distribution, and reproduction in any medium, provided the original work is properly cited. 